\title{
CDK2/5/9 Inhibitor CYC065
}

National Cancer Institute

\section{Source}

National Cancer Institute. CDK2/5/9 Inhibitor CYC065. NCI Thesaurus. Code C123902.

An orally bioavailable inhibitor of cyclin dependent kinases 2, 5 and 9 (CDK2/5/9), with potential antineoplastic and chemoprotective activities. Upon oral administration, CYC065 selectively binds to and inhibits the activity of CDK2, 5 and 9, which leads to inhibition of CDK2, 5 and 9-dependent cellular pathways, downregulation of genes involved in the prosurvival pathway, prevention of the activation of DNA double-strand break repair pathways, and induction of both cell cycle arrest and apoptosis. This inhibits the proliferation of CDK2/5/9-overexpressing tumor cells. In addition, CYC065 protects hematopoietic stem and progenitor cells (HSPCs), prevents myelosuppression, and preserves the function of the bone marrow. CDKs are serine/threonine kinases involved in the regulation of the cell cycle and may be overexpressed in certain cancer cell types; they play key roles in tumor cell proliferation, the regulation of transcription, and DNA damage repair. 